\title{
Statistical modelling for optimized lyophilization of Lactobacillus acidophilus strains for improved viability and stability using response surface methodology
}

\author{
Lakshminarayana Turuvekere Sadguruprasad ${ }^{1}(1)$ and Madhusudhan Basavaraj ${ }^{2^{*}}$ (])
}

\begin{abstract}
The awareness regarding use of probiotics for health benefits has created a huge market worldwide. The use of probiotic cultures and its success in commercial scale is relying on the techniques employed to ensure that the potential cultures with desired functional activity are stable and viable for longer period. The present study was undertaken to statistically evaluate the effect of lyoprotectant in the suspension media containing sucrose and reconstituted skim milk on the viability of Lactobacillus acidophilus strains. The central composite rotatable design of response surface methodology was used in evaluating the survival rate and viability even after 24 months' storage of three different lyophilized strains of $L$. acidophilus. We also determined the exclusive use of lyoprotectant on the survival of the lyophilized strains throughout the study period without altering any of the culture conditions. The most conspicuous result to emerge from the data is that the suspension medium composed of minimal amount of sucrose $(\sim 1.2 \%)$ in the reconstituted skim milk (6\%) was evident in maintaining a higher survival rate of lyophilized culture during 2-year storage. From this investigation, the optimized suspension media used to obtain the lyophilized concentrate of L. acidophilus could be recommended in designing dietary supplement with minimal modification for industrial application. This might reduce the manufacturing cost as well as storage loss occurring both in pharma and food sector.
\end{abstract}

Keywords: L. acidophilus, Lyoprotectors, Suspension media, Survival rate, Storage

\section{Introduction}

Probiotics are viable microorganisms gaining importance for optimum health benefits to alleviate the gut related disorders and modulate immune response (Morelli and Capurso 2012). Generally, commercialized probiotic products invariably consist of Lactobacilli, Bifidobacteria and also some yeasts for positive outcomes (Devi et al. 2015; Hudson et al. 2016; Shokri et al. 2015). The probiotic activity is shown by inhibiting the adherence of previously harbored bacteria, changing luminal $\mathrm{pH}$,

\footnotetext{
*Correspondence: madhusudhanbasavaraj@gmail.com

${ }^{2}$ Research Center for Nanoscience and Technology, Department of Studies and Research in Biochemistry \& Food Technology, Bio-Sciences Block, Davangere University, Shivagangotri, Davanagere, Karnataka 577002, India

Full list of author information is available at the end of the article
}

and reinforcing the body's natural defense by producing antibacterial peptides (Marchesi et al. 2015). In recent days, some clinical practitioners have begun to use probiotics for the treatment of many diseases (Hickson 2013; Hungin et al. 2013). The comparable outcome of the data between the in vitro models and in vivo human trials has substantiated that more attention on the strain specificity, therapeutic potential and promising methodologies in culturing the strains has to be paid to meet the commercial demand (Shanahan et al. 2012). The international scientific association for probiotics and prebiotics, states that any commercialized product or even marketable probiotic product must contain at least $10^{6}-10^{7} \mathrm{CFU}$ (colony forming unit) of viable probiotic per gram of the product during the time of consumption to exert probiotic effects on human health (Hill et al. 2014). 
Unfortunately, the viability problem crops-up during storage of the product. Therefore, the probiotics enriched products for commercial supply needs to be developed to meet the drawbacks in storage in all kinds of weather. Earlier researchers have emphasized the use of optimal preservation methods to be employed during long-term storage for the efficacy of probiotic products with higher viability of the microorganisms (Bigliardi and Galati 2013). Moreover, investigators have successfully attempted both lyophilization and spray-drying methods to dehydrate some selected probiotic cultures while exposing the culture to extreme environmental conditions (Martín et al. 2015). The simplest classical method, lyophilization has been widely used for the past several years to produce viable culture in dried powder form. However, the adverse effect of the process on the viability of many microorganisms is still inconclusive (Kandil and El Soda 2015). Apart from that recently, studies concerning to preparation of concentrated starter culture of well-known microorganisms by lyophilization was tried out for food application (Lee et al. 2016). The process has beneficial effects on the dried organisms as the entire process works at frozen temperature with no thermal degradation (Jalali et al. 2012). Earlier researchers have vigorously tested lyoprotective agents in order to improve the survival of bacteria during preservation (Lee et al. 2016). The continued efforts of the investigators began to add information that was much needed at the time of optimization considering the stability of microorganisms during the lyophilization process and long-term storage (She and Petti 2015).

Several researchers have tried to develop such a probiotic product in a cost-effective manner with high CFU. Regrettably, apart from few researchers, least attention has been paid to address the loss of crucial characteristics include sustainable probiotic activity, flavor, viable cells count, shelf-life on prolonged storage for gastrointestinal tract application (De Prisco and Mauriello 2016). Improvement of the process was continuous and few investigators have attempted to present the data using scalable statistical models to describe survival curves of well-considered microorganisms for post-lyophilized storage (Miyamoto-Shinohara et al. 2008; Silva et al. 2009). Such statistically definable models would allow the systematic analysis of any experimental data by using limited parameters of interest that would correlate between the parameters used with survival rates of microorganisms.

To overcome some of these gaps, we have employed central composite rotatable design (CCRD) of response surface methodology (RSM) as a tool to objectively evaluate the survival behavior of lyophilized microorganisms for 24-month storage.

\section{Materials and methods \\ Materials}

Lactobacillus MRS broth (M369), Lactobacillus MRS agar (M641), sucrose (GRM601), skim milk (M530), L-cysteine hydrochloride (TC058), phosphate buffered saline (M1866) were purchased from HiMedia Laboratories Pvt. Ltd. (Mumbai). Water used for all experiments was Milli-Q water. All other chemicals were of highest purity available and used without further purification.

\section{Microorganisms and culture conditions}

Lactobacillus acidophilus (NCDC 291), L. acidophilus (NCDC 015) and L. acidophilus (MTCC 10307) were procured from National Collection of Dairy Cultures (ICAR-NDRI, Karnal, India) and Microbial Type Culture Collection and Gene Bank (Institute of Microbial Technology, Chandigarh, India), respectively. The bacteria were kept at $-20{ }^{\circ} \mathrm{C}$ until used. All 3 strains were subcultured at least twice in MRS medias at $37^{\circ} \mathrm{C}$ just prior to experimental use.

\section{Experimental design and its statistical modeling}

Based on the previous studies, we have chosen sucrose and reconstituted skim milk as recommended lyoprotectants for lyophilization. We have adopted statistical modelling-an applied mathematical technique to optimize process by considering the affecting factors to achieve maximum response with relative significance. Thus, the five-level-two-factor CCRD of RSM (Kim and Rhee 2015) was used to optimize experimental design and the data is shown in Table 1 . The design includes 13 experimental runs consisting of 4 factorial points, wherein the factors used in full factorial runs are studied at +1 and -1 levels. Similarly, 4 axial points responsible to make design rotatable (Santos et al. 2015) and 5 center points involving all factors centered to help in determining the curvature and replication for estimating pure error (Additional file 1: Tables S1, S2, Figure S1). Verifiable models depicting the experimental results were developed using the data from the designed experiments. The model parameters were estimated using a factorial model for two factor (except survival rate which was linear model), each at level is as shown below

Table 1 The coded levels of sucrose and reconstituted skim milk for central composite experimental design

\begin{tabular}{lllllll}
\hline Factors [\% $(\mathbf{g} / 100 \mathrm{~mL})]$ & \multicolumn{4}{l}{ Coded levels } & & \\
\cline { 2 - 6 } & - alpha & Low & Center & High & + alpha \\
\hline $\begin{array}{l}\text { Sucrose (S) } \\
\text { Reconstituted skim milk } \\
\text { (SM) }\end{array}$ & -1.24264 & 0 & 3 & 6 & 7.24264 \\
\hline
\end{tabular}




$$
Y=\beta_{0}+\beta_{1} X_{1}+\beta_{2} X_{2}+\beta_{12} X_{1} X_{2}
$$

where $\mathrm{Y}$ is the expected value of the response variables, and $\beta_{0}, \beta_{1}, \beta_{2}$ and $\beta_{12}$ are the model parameters. The $X_{1}$, $X_{2}$ and $X_{12}$ are the coded factors evaluated. In this study, concentration of sucrose and reconstituted skim milk were selected as main factors. Initially only L. acidophilus (NCDC 291) culture was used for conducting the experiments and all the three L. acidophilus cultures (NCDC

\section{Cell viability assay}

Prior to the assay, lyophilized samples were added with suspension media by maintaining the original ratio and allowed for $10 \mathrm{~min}$ at room temperature for rehydration. Then, cells were diluted serially in MRS media and further incubated at $37^{\circ} \mathrm{C}$ for $24 \mathrm{~h}$ and the number of CFU/ $\mathrm{mL}$ was calculated (Qi et al. 2017; Shu et al. 2017). The procedure was repeated for the lyophilized samples in every 6 months until 2-year storage period. The survival rates were calculated and tabulated in Table 2 as follows:

$$
\text { Survival Rate }(\%)=\frac{\text { Viable count after lyophilization }(V C A L) \text { in CFU } / \mathrm{mL}}{\text { Viable count before lyophilization }(V C B L) \text { in CFU } / \mathrm{mL}} * 100
$$

291, NCDC 015 and MTCC 10307) separately were tested during optimization.

The statistical software package Design-Expert ${ }^{\circledR}$ (Version 7.0.0, Stat-Ease, Inc., Minneapolis, MN, USA) was used for analysis of the experimental data, to yield regression equation and determine optimum parameters by the plot of response contours and surface graphs. The response values were fitted to linear model for survival rate and a two-factorial interaction $(2 \mathrm{FI})$ model for rest of the responses after evaluating the results by Design-Expert ${ }^{\circledR}$ software.

\section{Lyophilization}

The bacterial cultures were collected from previously subcultured strains and inoculated into MRS media. The individual culture medium was incubated at $37^{\circ} \mathrm{C}$ for $24 \mathrm{~h}$. The cells were harvested at stationery growth phase by centrifuging at $5000 \mathrm{RPM}$ for $10 \mathrm{~min}$ at $4{ }^{\circ} \mathrm{C}$. The cells were washed twice by phosphate buffered saline and centrifuged. The washed cells were resuspended in suspension media containing reconstituted skim milk (SM) and sucrose (S) as lyoprotectors in recommended ratios by statistical model. However, in two runs negative concentration was suggested, however as its impossible to have negative concentration we decided to consider it as 0 concentration. The resultant homogeneous suspension was re-suspended in aliquots $(25 \mathrm{~mL})$ of each bacterial strain. Samples $(1-2 \mathrm{~mL})$ were taken from each aliquot and the number of $\mathrm{CFU} / \mathrm{mL}$ was determined by the plate dilution method using MRS media. Immediately, the aliquots were frozen in sterile cryovials at $-40{ }^{\circ} \mathrm{C}$ and stored for $24 \mathrm{~h}$. The frozen samples were dehydrated using lyophilizer (Labconco Corporation, USA) under high vacuum (0.05 mbar) for $48 \mathrm{~h}$. Lyophilized cells were stored in tightly sealed cryovials at different temperatures $\left(-80,-40,-20,4{ }^{\circ} \mathrm{C}\right.$ and at room temperature) in the dark for up to 24 months to assess the stability (Shu et al. 2018). We have presented the data for samples processed at $4{ }^{\circ} \mathrm{C}$ (and the data on other temperatures has not been presented here).

\section{Results}

The cell viability assessment is an important criterion in any microbial based pharma and food products of commercial interests. Till date, several studies have been undertaken by the researchers to improve the cell viability in a set of environmental conditions congenial for human use. In this investigation, we have chosen sucrose and reconstituted skim milk as recommended lyoprotectants prior to lyophilization followed by statistical modelling to optimize the process to achieve maximum response with relative significance. In the experimental design, thirteen runs were designed using CCRD. The design matrix and the corresponding results of CCRD experiments to determine the effects of the two independent variables are shown in Table 3.

Linear model for survival rate and 2FI model for rest was found to be adequate for the prediction of the

Table 2 Survival rates of $L$. acidophilus before and after lyophilization in 13 different formulations

\begin{tabular}{llllll}
\hline Runs & $\begin{array}{l}\text { Sucrose } \\
\%(\mathbf{g} / \mathbf{1 0 0} \mathbf{~} \mathbf{m})\end{array}$ & Skim milk & $\begin{array}{l}\text { VCBL } \\
\text { CFU/mL }\end{array}$ & VCAL & \multicolumn{2}{l}{$\begin{array}{l}\text { Survival rate } \\
\%\end{array}$} \\
\hline 1 & 0 & 0 & $1.98 \times 10^{5}$ & $9.91 \times 10^{4}$ & 50.03 \\
2 & 6 & 0 & $9.46 \times 10^{11}$ & $5.92 \times 10^{11}$ & 62.61 \\
3 & 0 & 6 & $8.90 \times 10^{11}$ & $6.02 \times 10^{11}$ & 67.63 \\
4 & 6 & 6 & $8.05 \times 10^{10}$ & $6.13 \times 10^{10}$ & 76.19 \\
5 & $-1.24^{\mathrm{a}}$ & 3 & $6.10 \times 10^{8}$ & $3.67 \times 10^{8}$ & 60.21 \\
6 & 7.24 & 3 & $1.63 \times 10^{11}$ & $1.12 \times 10^{11}$ & 68.83 \\
7 & 3 & $-1.24^{\mathrm{a}}$ & $6.02 \times 10^{8}$ & $3.47 \times 10^{8}$ & 57.62 \\
8 & 3 & 7.24 & $2.87 \times 10^{11}$ & $2.15 \times 10^{11}$ & 74.86 \\
9 & 3 & 3 & $1.73 \times 10^{10}$ & $1.14 \times 10^{10}$ & 65.96 \\
10 & 3 & 3 & $1.73 \times 10^{10}$ & $1.14 \times 10^{10}$ & 65.73 \\
11 & 3 & 3 & $1.73 \times 10^{10}$ & $1.14 \times 10^{10}$ & 65.97 \\
12 & 3 & 3 & $1.74 \times 10^{10}$ & $1.14 \times 10^{10}$ & 65.72 \\
13 & 3 & 3 & $1.74 \times 10^{10}$ & $1.14 \times 10^{10}$ & 65.45 \\
\hline
\end{tabular}

a As negative concentration cannot be achieved 0 was considered 
Table 3 Experimental design and responses after lyophilization

\begin{tabular}{|c|c|c|c|c|c|c|c|c|c|}
\hline \multirow[t]{3}{*}{ Run } & \multirow{2}{*}{\multicolumn{2}{|c|}{$\frac{\text { Factors }}{\%(g / 100 \mathrm{~mL})}$}} & \multicolumn{7}{|c|}{ Responses } \\
\hline & & & \multirow{2}{*}{$\begin{array}{l}\% \\
Y_{1}\end{array}$} & \multicolumn{6}{|c|}{$\log _{10} \mathrm{CFU} / \mathrm{mL}$} \\
\hline & $S$ & SM & & $Y_{2}$ & $Y_{3}$ & $Y_{4}$ & $Y_{5}$ & $Y_{6}$ & $Y_{7}$ \\
\hline 1 & 0.00 & 0.00 & 50.03 & 5.00 & 3.59 & 2.58 & 1.58 & 1.57 & 1.56 \\
\hline 2 & 6.00 & 0.00 & 62.61 & 11.77 & 10.70 & 10.67 & 10.64 & 10.59 & 10.55 \\
\hline 3 & 0.00 & 6.00 & 67.63 & 11.78 & 10.70 & 10.68 & 10.66 & 10.60 & 10.56 \\
\hline 4 & 6.00 & 6.00 & 76.19 & 10.79 & 9.09 & 9.06 & 9.00 & 8.77 & 8.72 \\
\hline 5 & $-1.24^{\mathrm{a}}$ & 3.00 & 60.21 & 8.56 & 7.56 & 7.53 & 7.49 & 7.42 & 7.39 \\
\hline 6 & 7.24 & 3.00 & 68.83 & 11.05 & 10.34 & 10.33 & 10.30 & 10.26 & 10.20 \\
\hline 7 & 3.00 & $-1.24^{\mathrm{a}}$ & 57.62 & 8.54 & 7.75 & 7.52 & 7.46 & 7.41 & 7.37 \\
\hline 8 & 3.00 & 7.24 & 74.86 & 11.33 & 10.40 & 10.34 & 10.32 & 10.30 & 10.23 \\
\hline 9 & 3.00 & 3.00 & 65.96 & 10.06 & 9.19 & 9.05 & 8.52 & 8.50 & 8.48 \\
\hline 10 & 3.00 & 3.00 & 65.73 & 10.06 & 9.19 & 9.05 & 8.52 & 8.50 & 8.48 \\
\hline 11 & 3.00 & 3.00 & 65.97 & 10.06 & 9.19 & 9.05 & 8.52 & 8.50 & 8.48 \\
\hline 12 & 3.00 & 3.00 & 65.72 & 10.06 & 9.19 & 9.05 & 8.52 & 8.50 & 8.48 \\
\hline 13 & 3.00 & 3.00 & 65.45 & 10.06 & 9.19 & 9.05 & 8.52 & 8.50 & 8.48 \\
\hline
\end{tabular}

${ }^{a}$ As negative concentration cannot be achieved 0 was considered

response variables. Final equations in terms of coded factors are;

$$
\begin{aligned}
& \mathrm{Y}_{1}=65.14+4.16 * \mathrm{~A}+6.94 * \mathrm{~B} \\
& \mathrm{Y}_{2}=9.93+1.16 * \mathrm{~A}+1.22 * \mathrm{~B}+-1.94 * \mathrm{AB} \\
& \mathrm{Y}_{3}=8.93+1.18 * \mathrm{~A}+1.16 * \mathrm{~B}+-2.18 * \mathrm{AB} \\
& \mathrm{Y}_{4}=8.77+1.30 * \mathrm{~A}+1.31 * \mathrm{~B}+-2.43 * \mathrm{AB} \\
& \mathrm{Y}_{5}=8.47+1.42 * \mathrm{~A}+1.43 * \mathrm{~B}+-2.68 * \mathrm{AB} \\
& \mathrm{Y}_{6}=8.42+1.40 * \mathrm{~A}+1.41 * \mathrm{~B}+-2.71 * \mathrm{AB} \\
& \mathrm{Y}_{7}=8.38+1.39 * \mathrm{~A}+1.40 * \mathrm{~B}+-2.71 * \mathrm{AB}
\end{aligned}
$$

where $\mathrm{Y}_{1}, \mathrm{Y}_{2}, \mathrm{Y}_{3}, \mathrm{Y}_{4}, \mathrm{Y}_{5}, \mathrm{Y}_{6}$ and $\mathrm{Y}_{7}$ are predicted survival rate (\%), $\log _{10} \mathrm{CFU} / \mathrm{mL}$ values obtained in viable count after lyophilization [VCAL], VCAL 1 month, VCAL 6 months, VCAL 12 months, VCAL 18 months and VCAL 24 months, respectively. Similarly, A is the code for sucrose concentration and B for reconstituted skim milk concentration. The regression equations (Eqs. 2-8) of models has been evaluated by using F-test for analysis of variance (ANOVA), which displayed that the regression equations were statistically significant with $95 \%$ confidence and prediction intervals $(P$ value $<0.05)$ (Table 4$)$.

Predicted $\mathrm{v} / \mathrm{s}$ actual plot of fitted models, survival rate (\%), $\log _{10} \mathrm{CFU} / \mathrm{mL}$ values obtained in viable count after lyophilization [VCAL], VCAL 1 month, VCAL 6 months, VCAL 12 months, VCAL 18 months and VCAL 24 months has been tabulated in Fig. 1, respectively.
The values of coefficient of determination $\left(\mathrm{R}^{2}\right)$ used to express the 'fitness' of the model's regression equations (Eqs. 2-8) are 0.947 for $Y_{1}, 0.969$ for $Y_{2}, 0.959$ for $Y_{3}$, 0.942 for $Y_{4}, 0.929$ for $Y_{5}, 0.932$ for $Y_{6}, 0.933$ for $Y_{7}$ which further pointed out that Eqs. (2)-(8) may be utilized for representing the true relationships among the variables. Since the calculated values of $R^{2}$ and adjusted- $R^{2}$ vary negligibly, models are composed of significant terms. An adequate precision ratio was determined by the software highlighting the signal (information of interest) to noise (random errors) ratio arising out of the data set. Adequate precision ratio greater than 4 is desirable and its values in the current investigation was 26.9 for survival rate, 30.9 for VCAL, 27.6 for VCAL 1 month, 22.7 for VCAL 6 months, 20.6 for VCAL 12 months, 21.2 for VCAL 18 months and 21.3 for VCAL 24 months, respectively. The above value shows that the originating model can be used to navigate in the design space. Further, low coefficient of variation (CV) values (2.63 for survival rate, 3.71 for VCAL, 4.91 for VCAL 1 month, 6.75 for VCAL 6 months, 8.49 for VCAL 12 months, 8.32 for VCAL 18 months and 8.3 for VCAL 24 months) showed the precision and reliability of the experiments. Above results indicated that these models will be helpful in further optimization by CCRD.

Low P-values $(<0.05)$ of each model term indicated the significant effect of factor on results. As per the P-values tabulated in Table 4, A (sucrose) and B (reconstituted skim milk) were showing the significance in the survival rate model. Further, in remaining models the significant terms were A (sucrose), B (reconstituted skim milk) and interaction variable $\mathrm{AB}$ (sucrose $\times$ reconstituted skim 
Table 4 Analysis of variance (ANOVA) of all response variables

\begin{tabular}{|c|c|c|c|c|c|}
\hline Responses & SS & DF & MS & $F$ & $P(\operatorname{Pr}>F)$ \\
\hline \multicolumn{6}{|l|}{ Survival rate (\%) } \\
\hline Model & 524.74 & 2 & 266.37 & 89.35 & $<0.0001^{* *}$ \\
\hline A-Sucrose & 138.87 & 1 & 138.87 & 47.29 & $<0.0001$ \\
\hline B-Reconstituted skim milk & 385.88 & 1 & 385.88 & 131.42 & $<0.0001$ \\
\hline Residual & 29.36 & 10 & 2.94 & & \\
\hline Lack of fit & 29.18 & 6 & 4.86 & 106.58 & $0.0002^{*}$ \\
\hline Pure error & 0.18 & 4 & 0.05 & & \\
\hline Cor total & 554.11 & 12 & & & \\
\hline \multicolumn{6}{|l|}{ VCAL } \\
\hline Model & 37.77 & 3 & 12.59 & 92.85 & $<0.0001^{* *}$ \\
\hline A-Sucrose & 10.81 & 1 & 10.81 & 79.70 & $<0.0001$ \\
\hline B-Reconstituted skim milk & 11.87 & 1 & 11.87 & 87.58 & $<0.0001$ \\
\hline$A B$ & 15.09 & 1 & 15.09 & 111.27 & $<0.0001$ \\
\hline Residual & 1.22 & 9 & 0.14 & & \\
\hline Lack of fit & 1.22 & 5 & 0.24 & & \\
\hline Pure error & 0.00 & 4 & 0.00 & & \\
\hline Cor total & 38.99 & 12 & & & \\
\hline \multicolumn{6}{|l|}{ VCAL 1 month } \\
\hline Model & 40.80 & 3 & 13.60 & 70.71 & $<0.0001^{* *}$ \\
\hline A-Sucrose & 11.09 & 1 & 11.09 & 57.68 & $<0.0001$ \\
\hline B-Reconstituted skim milk & 10.74 & 1 & 10.74 & 55.85 & $<0.0001$ \\
\hline$A B$ & 18.96 & 1 & 18.96 & 98.60 & $<0.0001$ \\
\hline Residual & 1.73 & 9 & 0.19 & & \\
\hline Lack of fit & 1.73 & 5 & 0.35 & & \\
\hline Pure error & 0.00 & 4 & 0.00 & & \\
\hline Cor total & 42.53 & 12 & & & \\
\hline \multicolumn{6}{|l|}{ VCAL 6 months } \\
\hline Model & 50.86 & 3 & 16.95 & 48.39 & $<0.0001^{* *}$ \\
\hline A-Sucrose & 13.57 & 1 & 13.57 & 38.73 & 0.0002 \\
\hline B-Reconstituted skim milk & 13.72 & 1 & 13.72 & 39.17 & 0.0001 \\
\hline$A B$ & 23.57 & 1 & 23.57 & 67.28 & $<0.0001$ \\
\hline Residual & 3.15 & 9 & 0.35 & & \\
\hline Lack of fit & 3.15 & 5 & 0.63 & & \\
\hline Pure error & 0.00 & 4 & 0.00 & & \\
\hline Cor total & 54.02 & 12 & & & \\
\hline \multicolumn{6}{|l|}{ VCAL 12 months } \\
\hline Model & 61.37 & 3 & 20.46 & 39.64 & $<0.0001^{* *}$ \\
\hline A-Sucrose & 16.20 & 1 & 16.20 & 31.40 & 0.0003 \\
\hline B-Reconstituted skim milk & 16.45 & 1 & 16.45 & 31.88 & 0.0003 \\
\hline$A B$ & 28.72 & 1 & 28.72 & 55.66 & $<0.0001$ \\
\hline Residual & 4.64 & 9 & 0.52 & & \\
\hline Lack of fit & 4.64 & 5 & 0.93 & & \\
\hline Pure error & 0.00 & 4 & 0.00 & & \\
\hline Cor total & 66.02 & 12 & & & \\
\hline \multicolumn{6}{|l|}{ VCAL 18 months } \\
\hline Model & 61.03 & 3 & 20.34 & 41.44 & $<0.0001^{* *}$ \\
\hline A-Sucrose & 15.69 & 1 & 15.69 & 31.97 & 0.0003 \\
\hline B-Reconstituted skim milk & 15.94 & 1 & 15.94 & 32.47 & 0.0003 \\
\hline$A B$ & 29.39 & 1 & 29.39 & 59.87 & $<0.0001$ \\
\hline
\end{tabular}

Table 4 (continued)

\begin{tabular}{lrrrrr}
\hline Responses & SS & DF & MS & F & P (Pr $>$ F $)$ \\
\hline Residual & 4.42 & 9 & 0.49 & & \\
Lack offit & 4.42 & 5 & 0.88 & & \\
Pure error & 0.00 & 4 & 0.00 & & \\
Cor total & 65.45 & 12 & & & \\
VCAL 24 months & & & & & \\
Model & 60.57 & 3 & 20.19 & 41.68 & $<0.0001^{* *}$ \\
A-Sucrose & 15.48 & 1 & 15.48 & 31.95 & 0.0003 \\
B-Reconstituted skim milk & 15.73 & 1 & 15.73 & 32.48 & 0.0003 \\
AB & 29.36 & 1 & 29.36 & 60.62 & $<0.0001$ \\
Residual & 4.36 & 9 & 0.48 & & \\
Lack of fit & 4.36 & 5 & 0.87 & & \\
Pure error & 0.00 & 4 & 0.00 & & \\
Cor total & 64.93 & 12 & & & \\
\hline DF & & &
\end{tabular}

$D F$ degrees of freedom, SS sum of squares, $M S$ mean square, $F$ and $P(P r>F) F$ and $P$ values, respectively

** $P<0.0001$, very significant; ${ }^{*} P<0.005$, significant

milk). The responses levels were decreasing with increase in the levels of factors as indicated by negative sign in Eqs. (2)-(8). The graphical representation of results in 2D contour plots and 3D surface plots of the regression model indicated the interactions between model terms A and B (Ramakrishnan et al. 2012, 2013).

The least count was found at the zero concentration of sucrose and reconstituted skim milk in all regression models (Fig. 2). The results stressed upon the exclusive use of sucrose and reconstituted skim milk without altering any of the culture conditions for having higher viable count. In addition, the viable count increased when maximum concentration of sucrose $(6 \%)$ and reconstituted skim milk (6\%) were used, individually. The viable count decreased when highest (at 6\%) concentrations of sucrose and reconstituted skim milk used together. The measure of concentrations of sucrose and reconstituted skim milk was crucial for viable count of $L$. acidophilus as represented in Fig. 2.

Figure 3 depicts an interaction plot of the model; where we noticed in Fig. 3b-g that when we used low concentrations of sucrose and reconstituted skim milk, the viability was low. Whereas, with increased concentration of sucrose $(6 \%)$ and minimal concentration of reconstituted skim milk; we could see increase in viable count but decrease in survival rate. We further noticed that when we used low sucrose concentration with high concentration of reconstituted skim milk, the viability was high and with increasing concentration of both sucrose and reconstituted skim milk above $\sim 5 \%$, the viability remains high regardless of reconstituted skim milk concentration. The Least Significant Difference (LSD) bars overlap at this 
end of the interaction graph, which implies that there is no significant difference in viability. The effect on survival rate due to the interaction of sucrose as well as reconstituted skim milk is presented in Fig. 3a. Figure 3b-g are indicative of interaction of two-factor shown by two characteristic non-parallel lines. The non-overlapping LSD bars indicated the significant effect of sucrose.

During diagnostics, we noticed through the normal plot for the residuals (Fig. 4), that the residuals for all responses exhibit no major deviations from the linearity showing that the residuals are normally distributed. This validated the statistical assumptions of the model.

\section{Optimization}

In order to optimize the multiple responses for achieving the desired point in the design region, we used the simultaneous optimization by RSM. The motive of the present investigation was to maximize $L$. acidophilus survival rate during lyophilization and storage. Design-Expert ${ }^{\circledR}$ software was employed for numerical optimization and seven solutions were suggested by the software. Out of which, we selected the default first solution that predicted the maximum response upon use of recommend ratio of sucrose $1.16 \%$ and reconstituted skim milk $6.0 \%$ in suspension medium (Fig. 5). The responses for NCDC 291, NCDC 015 and MTCC 10307 strains upon optimization are tabulated in Table 5. Confirmation test value results shows that there is a close agreement with predicted values at a $95 \%$ confidence and prediction interval establishing the models validity.

\section{Discussion}

In this work, we have optimized the lyophilization and storage conditions of 3 known L. acidophilus strains with proven commercial usage profile as a probiotic supplement. As reported by earlier researchers, the viability of probiotic cultures after lyophilization and storage depends on the several factors (Broeckx et al. 2016; Kailasapathy 2013). From our preliminary investigations, we have optimized the pre-lyophilization factors like inoculum size, culture phase and revival factors such as temperature, volume and time which are in agreement to previous studies (Montel Mendoza et al. 2014). In addition, we further examined the effect of lyoprotectors on viability and storage of post-lyophilized cultures.

We initiated our work with two lyoprotectors in the culture media composing of skim milk and sucrose in a cost-effective manner for better solubility of lyophilized powder as suggested by other researchers (Jalali et al. 2012). The present investigation revealed the dependency of both strain and lyoprotector on the survivability of $L$. acidophilus during lyophilization and storage. The tested lyoprotectors were effective in protecting the cells during the lyophilization process. After optimization, it appears
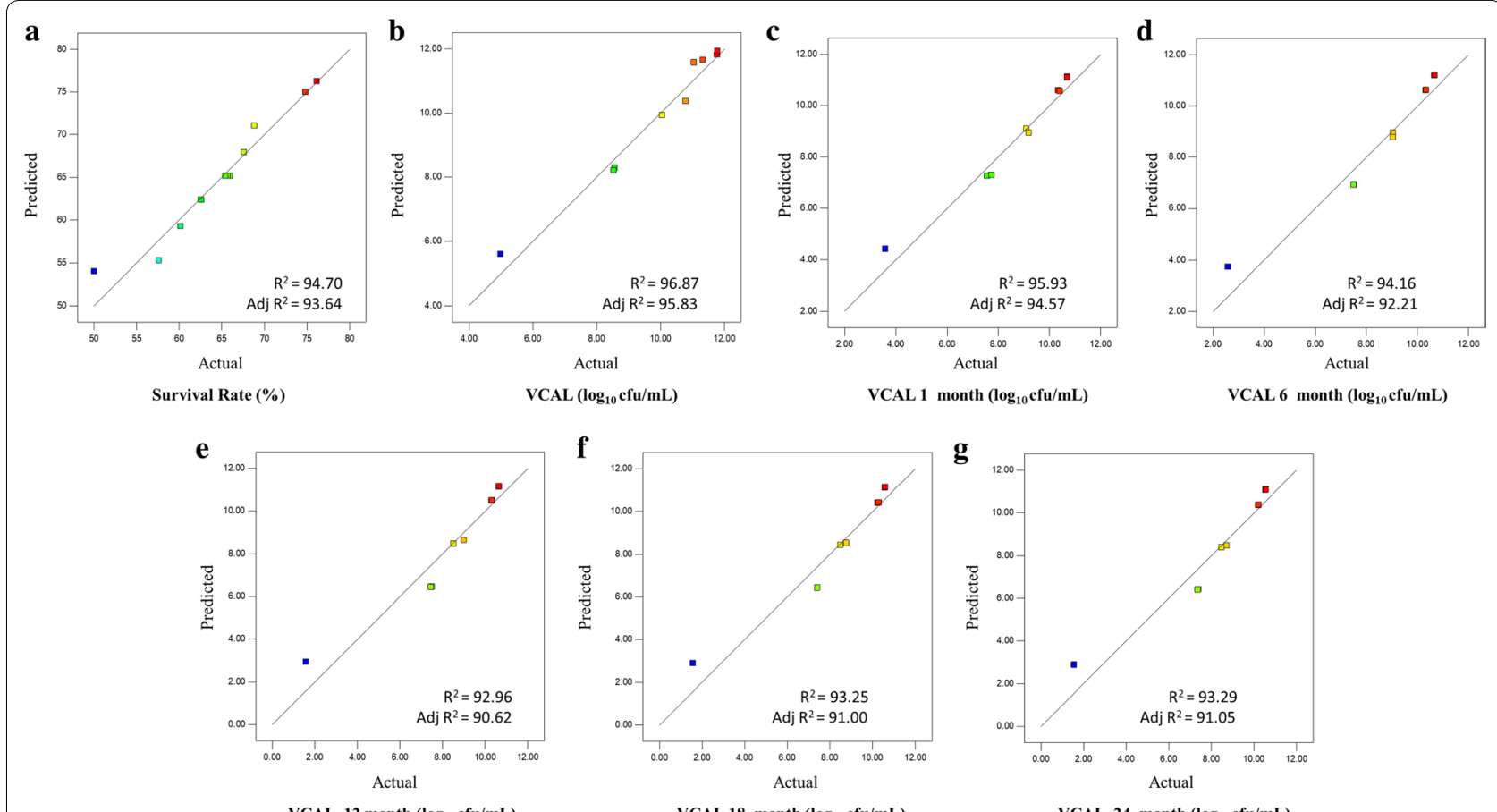

Fig. 1 Predicted vs. actual plot of: a survival rate (\%), $\log _{10}$ CFU/mL values obtained in b viable count after lyophilization [VCAL], cVCAL 1 month, d VCAL 6 months, e VCAL 12 months, f VCAL 18 months and $\mathbf{g}$ VCAL 24 months lyophilized probiotics powder 

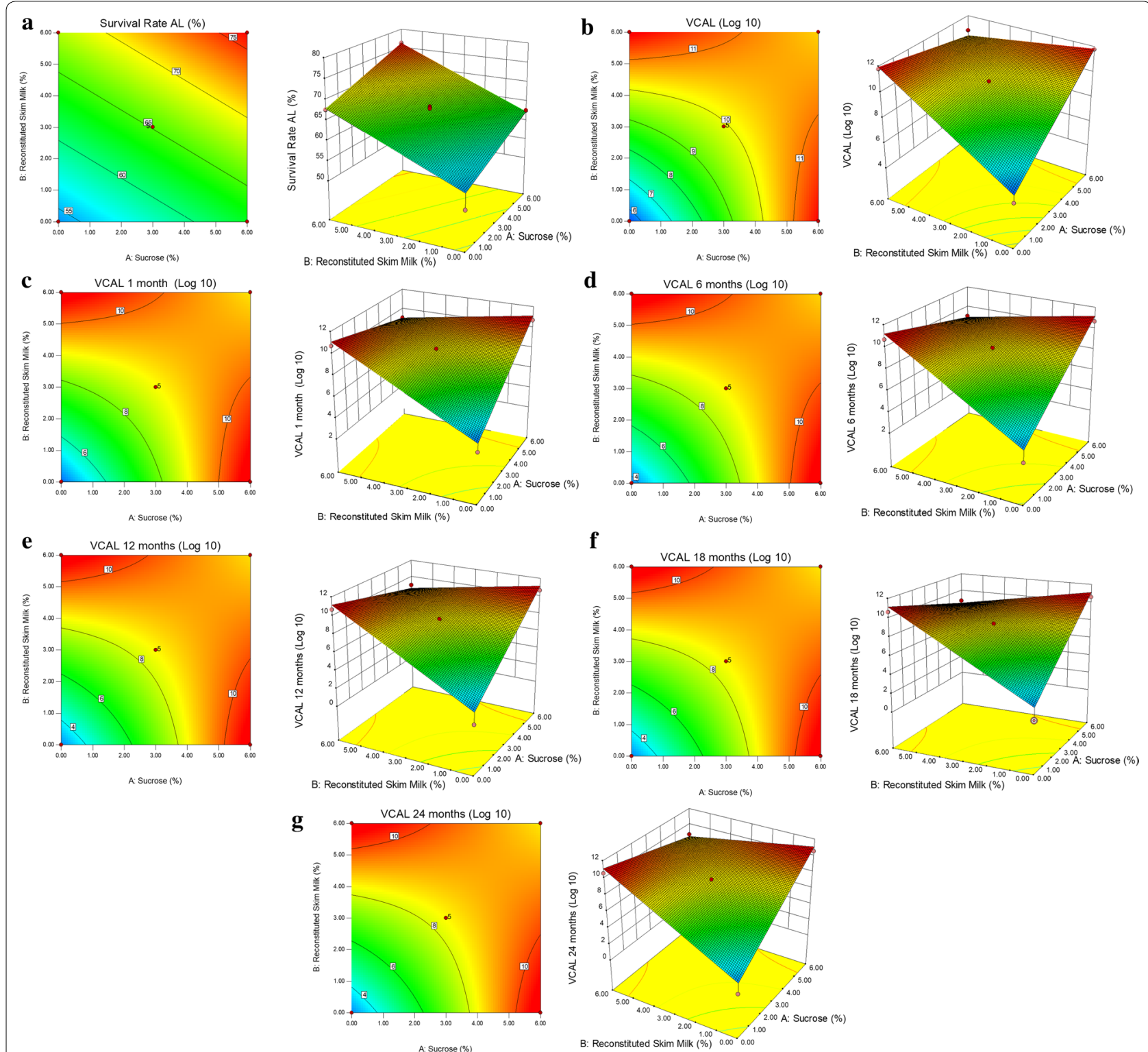

Fig. 2 Response surface (right) and contour (left) plots depicting effect of sucrose and reconstituted skim milk on a survival rate (\%), log ${ }_{10}$ CFU/mL values obtained in $\mathbf{b}$ viable count after lyophilization [VCAL], c VCAL 1 month, d VCAL 6 months, e VCAL 12 months, f VCAL 18 months and $\mathbf{g}$ VCAL 24 months lyophilized probiotics powder

at first instance the $\mathrm{Y} 2-\mathrm{Y} 7$ response values obtained for runs 1 and 2 (Table 3) remain more constant than optimized value (Table 5). On closer inspection, the overall survival rate of the cultures on optimization was far better than the test runs even after several repetitions. The superior performance was obtained with minimal concentration $(\sim 1.2 \%)$ of sucrose suspended in skim milk as compared to other formulations (Table 5). The use of RSM-CCRD in evaluating survival behavior of lactobacilli during storage resulted into viability plots that fit well with the applied model. From the application of statistical analysis, it confirms the effect of variable lyoprotectors on the estimated survival parameters of each individual strain among the three used.

It is evident from our investigation that addition of skim milk enhanced the survival rate with improved resistance to lyophilization stress in the presence of sucrose (Figs. 2, 3 ). The results obtained during the lyophilization process were consistent with earlier agreements indicating skim milk alone was not a good lyoprotectant during lyophilization of lactic acid bacteria (Otero et al. 2007). Similar studies have suggested the significant enhancement of 

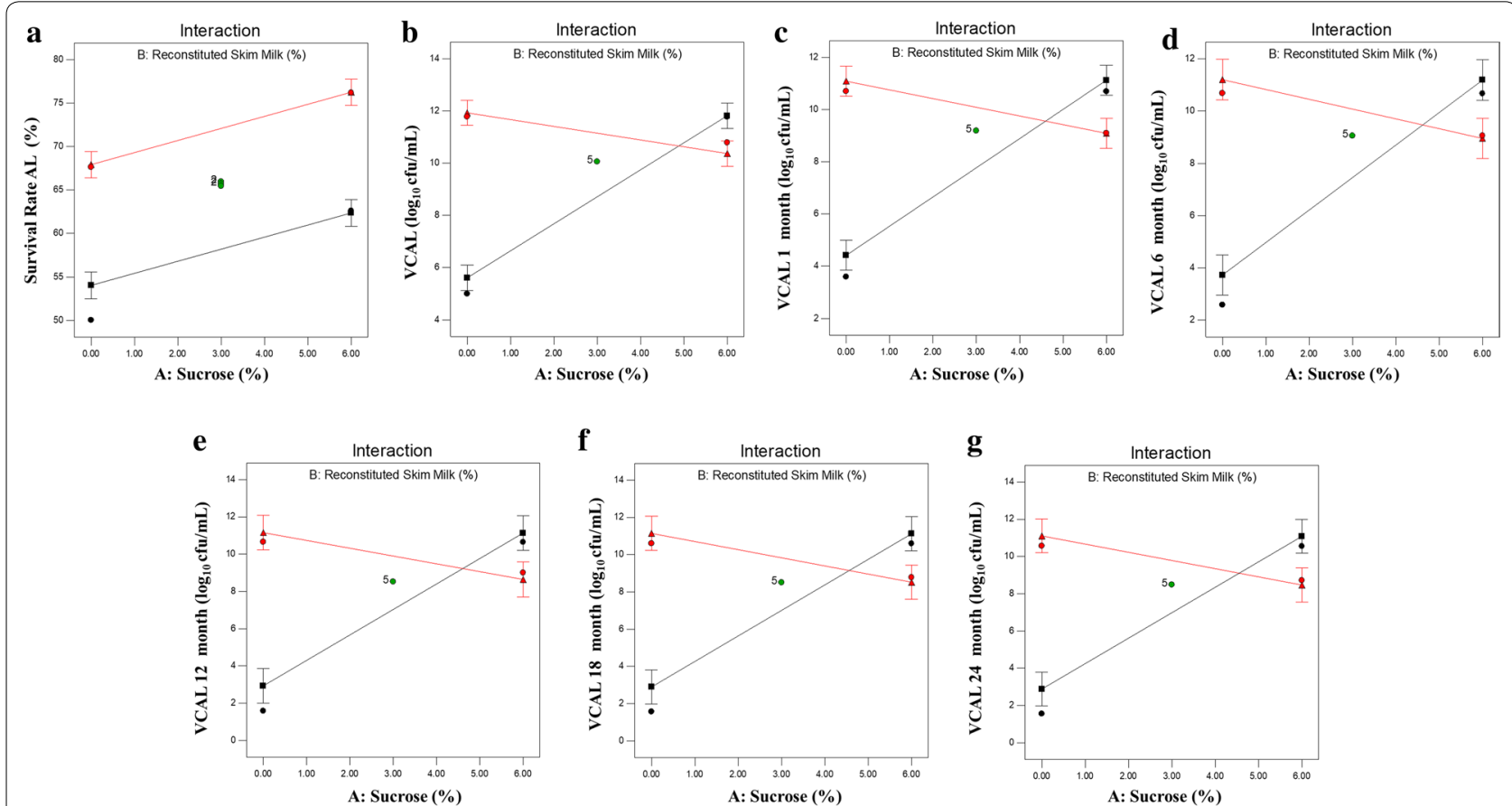

Fig. 3 Interaction of sucrose versus reconstituted skim milk on a Survival Rate (\%), log 10 CFU/mL values obtained in b Viable count after lyophilization[VCAL], c VCAL 1 month, d VCAL 6 months, e VCAL 12 months, f VCAL 18 months and $\mathbf{g}$ VCAL 24 months lyophilized probiotics powder

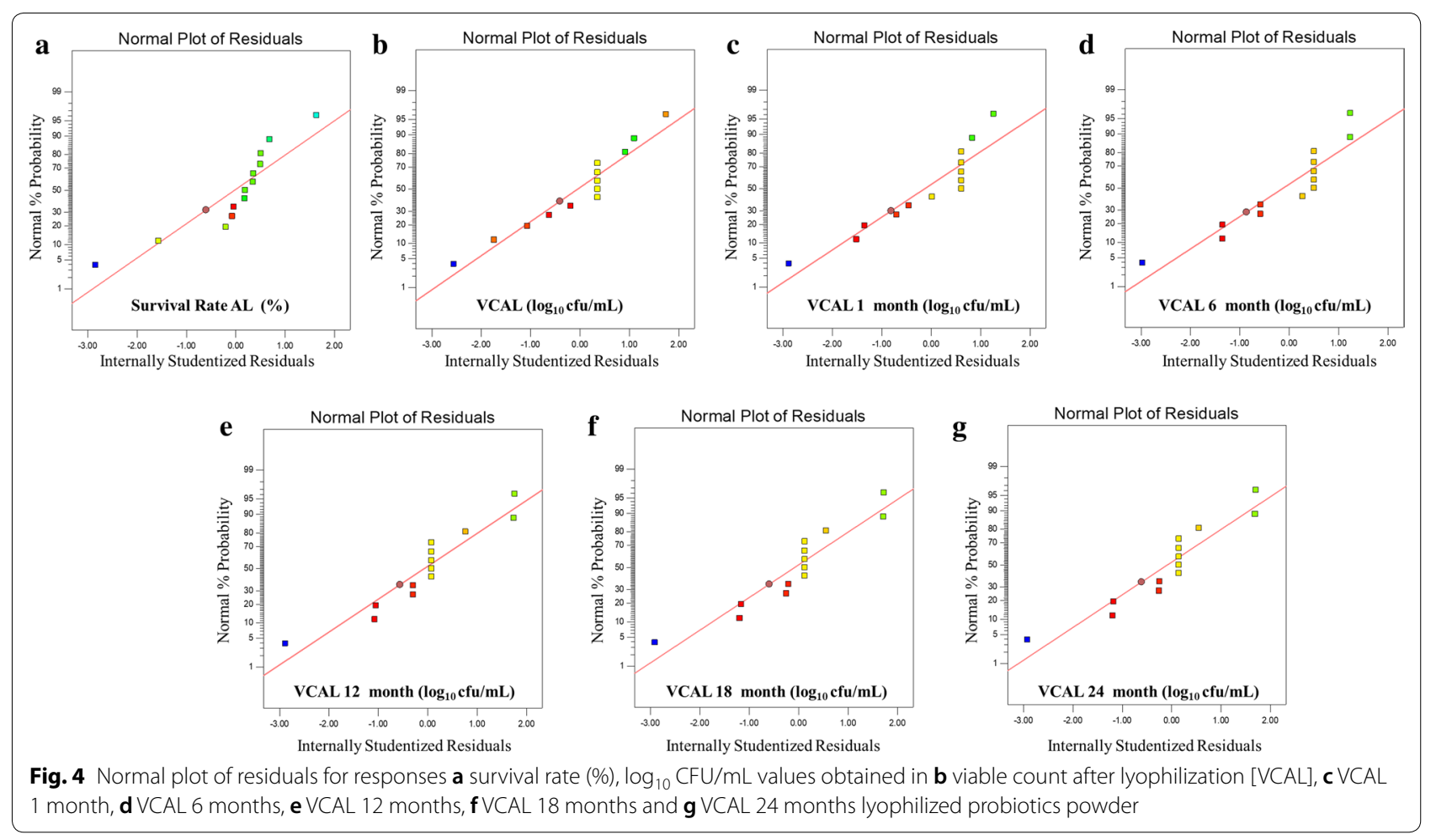




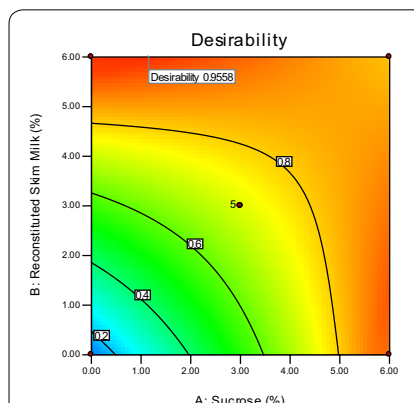

A: Sucrose $(\%)$
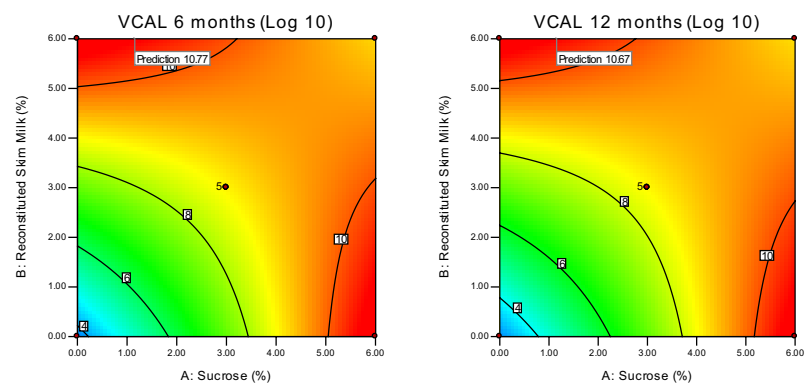
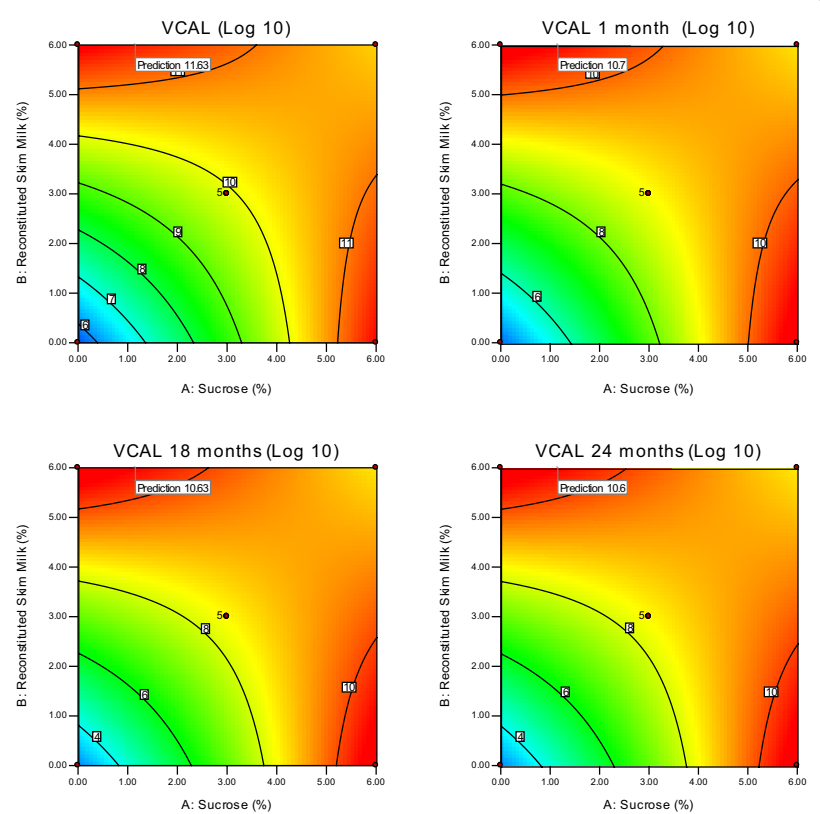

Fig. 5 Contour plots depicting the predicted optimized response values

Table 5 Optimum process and validation experiment results at $95 \%$ confidence and prediction interval

\begin{tabular}{|c|c|c|c|c|c|c|c|c|c|}
\hline Responses & Target & $\begin{array}{l}\text { Predicted } \\
\text { results }\end{array}$ & $\begin{array}{l}\text { Confirmation } \\
\text { test results } \\
\text { for NCDC } 291\end{array}$ & $\begin{array}{l}\text { Confirmation } \\
\text { test results } \\
\text { for NCDC } 015\end{array}$ & $\begin{array}{l}\text { Confirmation } \\
\text { test results } \\
\text { for MTCC } \\
10307\end{array}$ & $95 \% \mathrm{Cl}$ low & $95 \% \mathrm{Cl}$ high & 95\% PI low & 95\% PI high \\
\hline $\begin{array}{l}\text { Survival rate } \\
\text { AL }\end{array}$ & Maximize & 69.52 & 69.86 & 68.84 & 67.92 & 67.66 & 71.39 & 65.35 & 73.70 \\
\hline VCAL & Maximize & 11.63 & 11.33 & 11.04 & 11.05 & 11.14 & 12.12 & 10.66 & 12.59 \\
\hline VCAL 1 month & Maximize & 10.70 & 10.50 & 10.43 & 10.42 & 10.12 & 11.28 & 9.55 & 11.85 \\
\hline $\begin{array}{l}\text { VCAL } \\
6 \text { months }\end{array}$ & Maximize & 10.77 & 10.45 & 10.39 & 10.38 & 9.98 & 11.55 & 9.22 & 12.32 \\
\hline $\begin{array}{l}\text { VCAL } \\
12 \text { months }\end{array}$ & Maximize & 10.67 & 10.44 & 10.38 & 10.37 & 9.72 & 11.62 & 8.79 & 12.56 \\
\hline $\begin{array}{l}\text { VCAL } \\
18 \text { months }\end{array}$ & Maximize & 10.63 & 10.43 & 10.38 & 10.36 & 9.71 & 11.56 & 8.80 & 12.47 \\
\hline $\begin{array}{l}\text { VCAL } \\
24 \text { months }\end{array}$ & Maximize & 10.60 & 10.42 & 10.37 & 10.34 & 9.67 & 11.52 & 8.77 & 12.42 \\
\hline
\end{tabular}

protective abilities on addition of lyoprotectors in a mixture composed of skim milk, lactose, and sodium ascorbate during lyophilization (Chen et al. 2015).

Importantly, the storage conditions on the recovery of lyophilized cells were found to be critical for their survival (Goderska 2012). Also, it is clearly evident by the 2-year study that the lyophilized cells in a tightly wrapped cryovials placed in an airtight container and stored in dark at $4{ }^{\circ} \mathrm{C}$ was enough for the cultures to be viable. In addition, the stored cryovials containing lyophilized cells were able to resuscitate in rehydrating medium, more efficiently. The resultant data is indicative that microorganism's resistance against lyophilization and storage found to be highly variable and strain-dependent. Certain lyoprotectors have bearing among themselves in protecting cells throughout lyophilization and storage. The current work is being considered to link with the formulations of symbiotic macrodevices [SynMacDev] for eubiosis of gut microflora, is underway.

In summary, optimization of lyoprotectants during lyophilization and long-term storage of $L$. acidophilus was investigated using statistical modelling. The RSM-CCRD was used for statistical analysis and optimization of the process. The concentration of sucrose and reconstituted 
skim milk had a potential bearing on the survival of $L$. acidophilus was evaluated over a period of 2 years. The most conspicuous result to emerge from the data is that the suspension medium composed of minimal concentration of sucrose $(\sim 1.2 \%)$ and reconstituted skim milk (6\%) was found to be significantly effective in maintaining high degree of survival even after lyophilization and stable for longer storage at $4{ }^{\circ} \mathrm{C}$. The developed regimen substantiates the necessity of the preadaptation of the individual strains to gastrointestinal conditions by mimicking the environmental factors include temperature and $\mathrm{pH}$. From this investigation, the optimized suspension media used to obtain the lyophilized concentrate of $L$. acidophilus could be recommended in designing dietary supplement with minimal modification for industrial application. Thus reducing the manufacturing cost as well as storage loss occurring both in pharma and food sector.

\section{Additional file}

Additional file 1. Design Summary \& Evaluation with additional tables and figure.

\section{Abbreviations}

CFU: colony forming unit; CCRD: central composite rotatable design; RSM: response surface methodology; $2 \mathrm{FI}$ : two factorial interaction; SM: reconstituted skim milk; S: sucrose; VCAL: viable count after lyophilization; LSD: least significant difference.

\section{Authors' contributions}

LTS and BMS conceived the method and designed the experiments. LTS performed the experiments. LTS and BMS analyzed the results and wrote the manuscript. Both authors read and approved the final manuscript.

\section{Author details}

${ }^{1}$ Research Center for Nanoscience and Technology, Department of Studies and Research in Biochemistry, Bio-Sciences Block, Davangere University, Shivagangotri, Davanagere, Karnataka 577002, India. ${ }^{2}$ Research Center for Nanoscience and Technology, Department of Studies and Research in Biochemistry \& Food Technology, Bio-Sciences Block, Davangere University, Shivagangotri, Davanagere, Karnataka 577002, India.

\section{Acknowledgements}

The authors thank the Research Centre for Nanoscience and Technology, Davangere University for providing laboratory facility and encouragement during this study. The authors thank the Grant Agency, University Grant Commission, New Delhi, India for supporting this research through Major Research Project with Grant No.: F.No.41-676/2012 (SR).

\section{Competing interests}

The authors declare that they have no competing interests.

\section{Availability of data and materials}

The dataset(s) supporting the conclusions of this article is(are) included within the article and its additional file(s).

\section{Consent for publication}

Not applicable.
Ethics approval and consent to participate

This article does not contain any studies with human participants or animals performed by any of the authors.

\section{Funding}

This study was funded by University Grant Commission, New Delhi with Grant No.: F.No.41-676/2012 (SR).

\section{Publisher's Note}

Springer Nature remains neutral with regard to jurisdictional claims in published maps and institutional affiliations.

Received: 15 March 2018 Accepted: 2 August 2018

Published online: 10 August 2018

\section{References}

Bigliardi B, Galati F (2013) Innovation trends in the food industry: the case of functional foods. Trends Food Sci Technol 31(2):118-129. https://doi. org/10.1016/j.tifs.2013.03.006

Broeckx G, Vandenheuvel D, Claes IJ, Lebeer S, Kiekens F (2016) Drying techniques of probiotic bacteria as an important step towards the development of novel pharmabiotics. Int J Pharm 505(1):303-318

Chen H, Chen S, Li C, Shu G (2015) Response surface optimization of lyoprotectant for Lactobacillus bulgaricus during vacuum freeze-drying. Prep Biochem Biotechnol 45(5):463-475

De Prisco A, Mauriello G (2016) Probiotication of foods: a focus on microencapsulation tool. Trends Food Sci Technol 48:27-39. https://doi.org/10.1016/j. tifs.2015.11.009

Devi SM, Archer AC, Halami PM (2015) Screening, characterization and in vitro evaluation of probiotic properties among lactic acid bacteria through comparative analysis. Probiotics Antimicrob Proteins 7(3):181-192. https ://doi.org/10.1007/s12602-015-9195-5

Goderska K (2012) Different methods of probiotics stabilization probiotics. InTech, Rijeka

Hickson M (2013) Examining the evidence for the use of probiotics in clinical practice. Nurs Stand 27(29):35-41. https://doi.org/10.7748/ns201 3.03.27.29.35.e6363

Hill C, Guarner F, Reid G, Gibson GR, Merenstein DJ, Pot B, Morelli L, Canani RB, Flint HJ, Salminen S, Calder PC, Sanders ME (2014) Expert consensus document: the International Scientific Association for Probiotics and Prebiotics consensus statement on the scope and appropriate use of the term probiotic. Nat Rev Gastroenterol Hepatol 11(8):506-514. https://doi. org/10.1038/nrgastro.2014.66

Hudson LE, McDermott CD, Stewart TP, Hudson WH, Rios D, Fasken MB, Corbett AH, Lamb TJ (2016) Characterization of the probiotic yeast Saccharomyces boulardii in the healthy mucosal immune system. PLOS ONE 11 (4):e0153351. https://doi.org/10.1371/journal.pone.0153351

Hungin APS, Mulligan C, Pot B, Whorwell P, Agréus L, Fracasso P, Lionis C, Mendive J, Philippart de Foy JM, Rubin G, Winchester C, de Wit N (2013) Systematic review: probiotics in the management of lower gastrointestinal symptoms in clinical practice-an evidence-based international guide. Aliment Pharmacol Ther 38(8):864-886. https://doi.org/10.1111/ apt. 12460

Jalali M, Abedi D, Varshosaz J, Najjarzadeh M, Mirlohi M, Tavakoli N (2012) Stability evaluation of freeze-dried Lactobacillus paracasei subsp. tolerance and Lactobacillus delbrueckii subsp. bulgaricus in oral capsules. Res Pharm Sci 7(1):31

Kailasapathy K (2013) Commercial sources of probiotic strains and their validated and potential health benefits - a review. Int J Fermented Foods 2(1):1

Kandil S, El Soda M (2015) Influence of freezing and freeze drying on intracelIular enzymatic activity and autolytic properties of some lactic acid bacterial strains. Adv Microbiol 05(06):371-382. https://doi.org/10.4236/ aim.2015.56039

Kim SA, Rhee MS (2015) Predictive model and optimization of a combined treatment of caprylic acid and citric acid for the reduction of Escherichia coli O157:H7 using the response surface methodology. Int J Food Microbiol 197:9-14. https://doi.org/10.1016/j.jifoodmicro.2014.12.006 
Lee S-B, Kim D-H, Park H-D (2016) Effects of protectant and rehydration conditions on the survival rate and malolactic fermentation efficiency of freeze-dried Lactobacillus plantarum JH287. Appl Microbiol Biotechnol 100(18):7853-7863. https://doi.org/10.1007/s00253-016-7509-5

Marchesi JR, Adams DH, Fava F, Hermes GDA, Hirschfield GM, Hold G, Quraishi MN, Kinross J, Smidt H, Tuohy KM, Thomas LV, Zoetendal EG, Hart A (2015) The gut microbiota and host health: a new clinical frontier. Gut 65(2):330-339. https://doi.org/10.1136/gutjnl-2015-309990

Martín MJ, Lara-Villoslada F, Ruiz MA, Morales ME (2015) Microencapsulation of bacteria: a review of different technologies and their impact on the probiotic effects. Innov Food Sci Emerg Technol 27:15-25. https://doi. org/10.1016/j.ifset.2014.09.010

Miyamoto-Shinohara Y, Sukenobe J, Imaizumi T, Nakahara T (2008) Survival of freeze-dried bacteria. J Gen Appl Microbiol 54(1):9-24. https://doi. org/10.2323/jgam.54.9

Montel Mendoza G, Pasteris S, Otero M, Fatima Nader-Macías M (2014) Survival and beneficial properties of lactic acid bacteria from raniculture subjected to freeze-drying and storage. J Appl Microbiol 116(1):157-166

Morelli L, Capurso L (2012) FAO/WHO guidelines on probiotics. J Clin Gastroenterol 46:S1-S2. https://doi.org/10.1097/mcg.0b013e318269fdd5

Otero MC, Espeche MC, Nader-Macías ME (2007) Optimization of the freezedrying media and survival throughout storage of freeze-dried Lactobacillus gasseri and Lactobacillus delbrueckii subsp. delbrueckii for veterinarian probiotic applications. Process Biochem 42(10):1406-1411

Qi K, Chen H, Wan H, Hu M, Wu Y (2017) Response surface optimization of lyoprotectant from amino acids and salts for bifidobacterium bifidum during vacuum freeze-drying. Acta Univ Cibiniensis 21(2):3-10

Ramakrishnan V, Goveas LC, Prakash M, Halami PM, Narayan B (2012) Optimization of conditions for probiotic curd formulation by Enterococcus faecium MTCC 5695 with probiotic properties using response surface methodology. J Food Sci Technol 51(11):3050-3060. https://doi. org/10.1007/s13197-012-0821-x

Ramakrishnan V, Goveas LC, Narayan B, Halami PM (2013) Comparison of lipase production by Enterococcus faecium MTCC 5695 and Pediococcus acidilactici MTCC 11361 using fish waste as substrate: optimization of culture conditions by response surface methodology. ISRN Biotechnol 2013:1-9. https://doi.org/10.5402/2013/980562

Santos FG, Mendonça LA, Mantovani HC (2015) A central composite rotatable design (CCRD) approach to study the combined effect of antimicrobial agents against bacterial pathogens. World J Microbiol Biotechnol 31(9):1361-1367. https://doi.org/10.1007/s11274-015-1884-4

Shanahan F, Dinan TG, Ross P, Hill C (2012) Probiotics in transition. Clin Gastroenterol Hepatol 10(11):1220-1224. https://doi.org/10.1016/j. cgh.2012.09.020

She RC, Petti CA (2015) Procedures for the storage of microorganisms manual of clinical microbiology, 11 th edn. American Society of Microbiology, Washington, DC, pp 161-168

Shokri Z, Fazeli MR, Ardjmand M, Mousavi SM, Gilani K (2015) Factors affecting viability of Bifidobacterium bifidum during spray drying. DARU J Pharm Sci. https://doi.org/10.1186/s40199-014-0088-z

Shu G, Zhang B, Hui Y, Chen H, Wan H (2017) Optimization of cryoprotectants for Streptococcus thermophilus during freeze-drying using Box-Behnken experimental design of response surface methodology. Emir J Food Agric 29(4):256

Shu G, Wang Z, Chen L, Wan H, Chen H (2018) Characterization of freeze-dried Lactobacillus acidophilus in goat milk powder and tablet: optimization of the composite cryoprotectants and evaluation of storage stability at different temperature. LWT 90:70-76

Silva RR, Moraes CA, Bessan J, Vanetti MCD (2009) Validation of a predictive model describing growth of Salmonella in enteral feeds. Braz J Microbiol 40(1):149-154. https://doi.org/10.1590/s1517-83822009000100026

\section{Submit your manuscript to a SpringerOpen ${ }^{\circ}$ journal and benefit from:}

- Convenient online submission

- Rigorous peer review

- Open access: articles freely available online

- High visibility within the field

- Retaining the copyright to your article

Submit your next manuscript at $\boldsymbol{\nabla}$ springeropen.com 